\title{
Correspondence
}

\section{Standardization of insulin preparations and syringes}

Sir,

We wish to comment on the article by McKinlay and Farquhar (1976) and to give the opinion of the International Study Group of Diabetes in Children and Adolescents - the association of paediatric diabetologists. At the meeting of the study group held in Belgium 25-26 June 1976, one of the sessions was entitled 'Standardization of types of insulins and syringes' (moderator, Prof. $\varnothing$. Aagenaes, Oslo).

Of course, the dual U-40/U-80 syringe is a source of dosage errors and the type of syringe with 2 graduated scales has to be discarded (Ernould et al., 1973; Rosenbloom, 1974; Shainfeld, 1975). The use of U-100 insulins is certainly of great interest for diabetic adolescents and adults who need a larger number of units each day. But in children receiving small doses of insulin, the stuay group preferred the U-40 insulins because of greater accuracy in measuring the dose in the syringe, since a smaller concentration of insulin per $\mathrm{ml}$ allows easier reading of graduations on the syringe.

So paediatric diabetologists of the study group would like to maintain, in Europe, the existence of U-40 insulins for diabetic children. The ideal syringe must be graduated at 1-U increments, with graduations not too close, for only a single strength of insulin, and with no dead space (Shainfeld, 1975).

\section{H. DORCHY*, Ch. ERNOULD, and} H. LOEB

International Study Group of Diabetes in Children and Adolescents

(*Service de Pédiatrie, Hôpital Universitaire St. Pierre, Rue Haute, 320, B-1000, Brussels, Belgium.)

\section{References}

Ernould, Ch., Dorchy, H., Francois, B., Geussens, H., Mozin, M. J., and Loeb, H. (1973). Guide du Jeune Diabétique. Revue Médicale de Liège, Liège.

McKinlay, I., and Farquhar, J. W. (1976). Use of 100 units/ $\mathrm{ml}$ insulin in treatment of diabetic children. Archives of Disease in Childhood, 51, 796-798.

Rosenbloom, A. L. (1974). Advances in commercial insulin preparations. American Journal of Diseases of Children, 128, 631-633.

Shainfeld, F. J. (1975). Errors in insulin doses due to the design of insulin syringes. Pediatrics, 56, 302-303.

\section{Dr. Farquhar comments:}

Our Belgian colleagues differ only in that they, like other Europeans, wish to retain U-40 preparations. I understand that there may be good economic reasons for this as well as the practical one of measuring low doses.
Colleagues in adult medicine however may argue to retain U-80 or even U-20 so that no change occurs. The International Diabetes Federation compromised in 1976 by accepting both U-100 and U-40 which may mean that North Americans will polarize toward one, Europeans toward another, and the insulin manufacturers make for one or other market. The British Standard 1619 insulin syringes ( 20 graduations in $1 \mathrm{ml} ; 40$ graduations in $2 \mathrm{ml}$ ) have existed for over 20 years so that British children and parents are more fortunate than many in Europe who must still contend with 2 or even 3 graduation scales at the whim of manufacturers and nonconformist physicians. The British Diabetic Association would like to see all disposable insulin syringes in Britain conform to 1619 type. U-100 insulin was measured accurately enough down to 4 units (as in our Table 1). The syringes were well marked and of such a diameter as to space out the graduations. Parents preferred exerting a little more manipulative skill to risking their arithmetic in the way made necessary with varying insulin concentrations.

The insulin market has become as complex as the baby food one and is a sight more dangerous. If all currently available insulins have to exist in 2-3 concentrations in packets gay as coloured bunting at a regatta, some children will suffer, sometimes permanently, and the very real anxieties of their parents will continue. The exact concentration may matter more to manufacturers than to physicians. For the sake of diabetic children, their parents, nurses, and doctors, let us agree with industry on one concentration (U-50?) for all diabetics and on standardized syringes for all. If we compromised on U-50 in Europe and U-100 in North America the same standardized syringe could be used for both ( 50 graduations in $1 \mathrm{ml}$ ) or at least life would be less confusing for those whose diabetic practice is North Atlantic in outlook.

J. W. FARQUHAR Department of Child Life and Health, University of Edinburgh, 17 Hatton Place, Edinburgh EH9 1UW.

\section{Stool sugars and $p \mathrm{H}$ in breast-fed neonates}

Sir,

We have read with interest the article by Drs. Counahan and Walker-Smith on stool and urinary sugars in normal neonates (Archives, 1976, 51, 517). They suggest that the greater proportion of breast-fed babies observed to have reducing substances in their stools may be related to the higher concentration of lactose in breast milk. In fact, the formula (prepacked half-cream Cow and Gate) given to the bottle-fed babies did not contain less lactose than human milk $(7 \cdot 1 \mathrm{~g} / 100 \mathrm{ml})$.

We have recently analysed specimens of stools from 78 normal term neonates ranging in age from 2 to 15 